\title{
Hội thảo Thúc đẩy khoa học mở tại Đông Nam Á
}

\section{Nguyễn Thanh Thanh Huyền}

Phenikaa University

Hà Nội, ngày 29 tháng 10 năm 2021.

*Nguồn: https://isr.phenikaa-uni.edu.vn/vi/post/tin-tuc/tin-tuc/sub-tintuc/hoi-thao-thuc-day-khoa-hoc-mo-tai-dong-nam-a

ISR Phenikaa (29-10-2021) - Ngày 29/10/2021, Hội thảo Advancing Science in Southeast Asia đã chính thức khai mạc trực tuyến trên nền tảng Zoom với mục tiêu tạo một cộng đồng để các nhà khoa học, diễn giả từ các quốc gia trong và ngoài khu vực Đông Nam Á cùng khám phá, học hỏi, và đóng góp ý kiến về các vấn đề và giải pháp để phát triển chất lượng nghiên cứu và đảm bảo khoa học có những ảnh hưởng tích cực đến xã hội.

Đây là buổi hội thảo do hai tổ chức Mạng lưới Khoa học mở Đông Nam Á (Southeast Asian Network for Open Science) và Hội đồng Khoa học Quốc tế Châu Á Thái Bình Dương (International Science Council Asia Pacific) đứng ra chủ trì, cùng với sự phối hợp của các đối tác tại các quốc gia khác. Tại Việt Nam, đơn vị phối hợp tổ chức là Trung tâm Nghiên cứu Xã hội Liên ngành, Trường Đại học Phenikaa.

Phiên sáng của hội thảo được thiết kế riêng để trao đổi với các chuyên gia hàng đầu về các vấn đề chung của Đông Nam Á, bao gồm việc hợp tác để tạo chuẩn chuất lượng nghiên cứu, các nhóm nghiên cứu, tạp chí khoa học riêng của khu vực, và phát triển khoa học mở. Hai khách mời đại diện cho Việt Nam là TS. Phạm Hùng Hiệp (EdLab và Trường Đại học Phú Xuân) và ThS. Hồ Mạnh Toàn (Trường Đại học Phenikaa).

Hai đại diện đều nhấn mạnh vào tầm quan trọng của khoa học mở kết nối cộng đồng khoa học với công chúng. Với những trải nghiệm về sự thiếu vắng truyền thông khoa học ở Việt Nam, TS. Phạm Hùng Hiệp đề xuất cộng đồng cùng chung tay tạo một nền tảng truyền thông khoa học chung cho khu vực, mở đường cho khoa học mở phát triển. Tiếp nối cho ý kiến này, ThS. Hồ Mạnh Toàn cho rằng cộng đồng còn nhiều định kiến đối với khoa học mở, cho dù khoa học mở, và các nhà xuất bản mở, đã có rất nhiều cải tiến các quy trình bình duyệt và xuất bản khoa học.

Hình ảnh phiên họp tại Việt Nam 


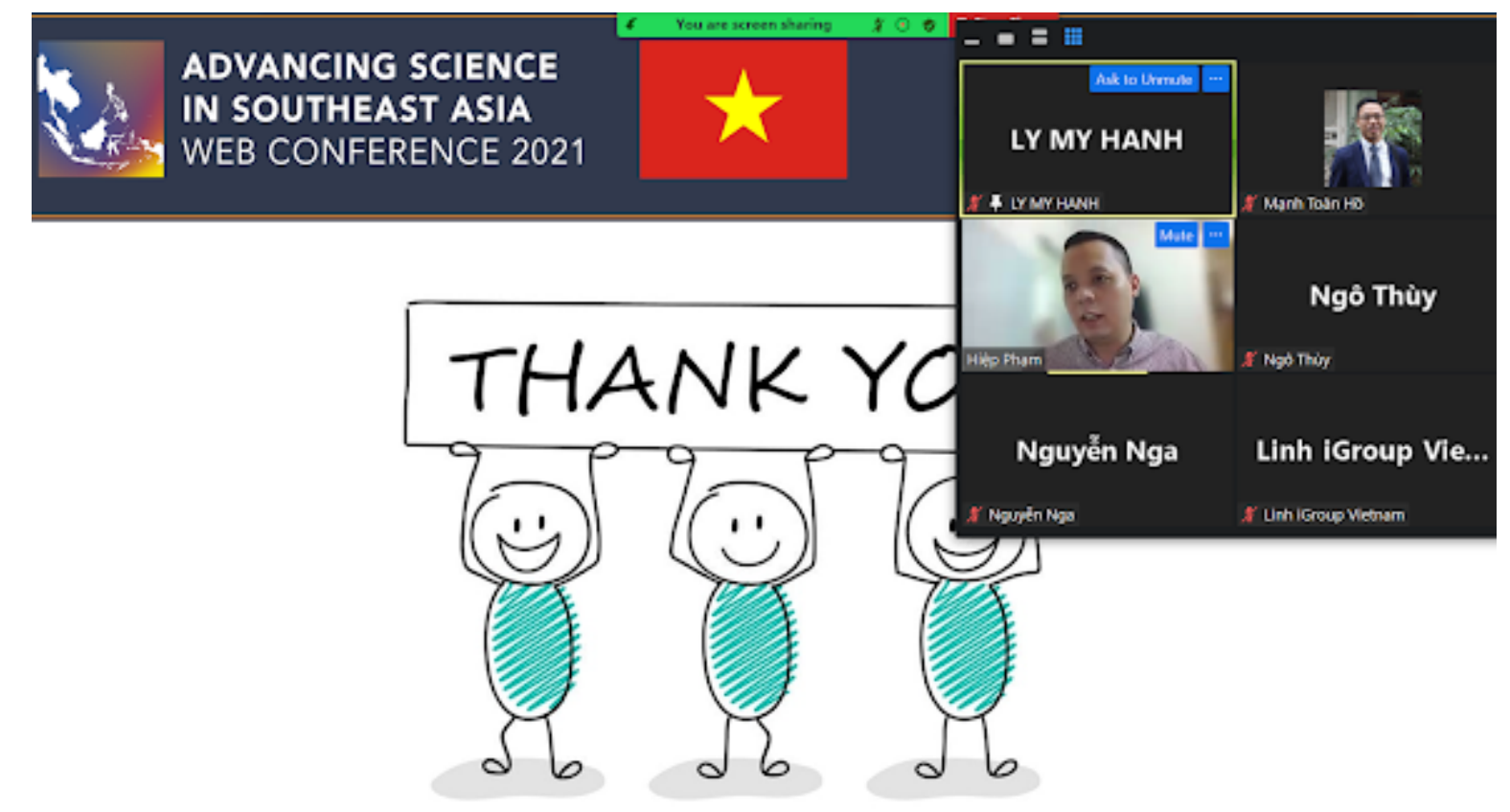

Vào buổi chiều, các nhà khoa học ở từng quốc gia khác nhau sẽ thảo luận bàn tròn để có thể trao đổi sâu hơn về các khó khăn khi làm nghiên cứu tại mỗi quốc gia và hướng giải quyết. Tại Việt Nam, phiên hội thảo được chủ trì bởi TS. Phạm Hùng Hiệp, ThS. Hồ Mạnh Toàn và chị Nguyễn Thùy Linh (đại diện từ iGroup). Đã có 28 nhà khoa học, giảng viên và chuyên gia có kinh nghiệm về xây dựng chính sách khoa học tại Việt Nam, tham gia, chia sẻ về các khó khăn, thách thức cũng như gợi ý các giải pháp để có thể thực hiện các nghiên cứu chất lượng cao, có ảnh hưởng sâu rộng tại Việt Nam.

Buổi hội thảo là một trong những nỗ lực đầu tiên để giúp khoa học Đông Nam Á, và khoa học Việt Nam nói riêng, có thể hiểu thêm về xu hướng khoa học mở, cũng như các câu chuyện xung quanh nó. Độc giả quan tâm có thể tham khảo một số tài liệu sau [1-3].

\section{Tài liệu tham khảo:}

[1] Vuong QH. (2020). Reform retractions to make them more transparent. Nature, 582(7811), 149.

[2] Vuong QH. (2018). The (ir)rational consideration of the cost of science in transition economies. Nature Human Behaviour, 2(1), 5 .

[3] Vuong QH. (2019). Breaking barriers in publishing demands a proactive attitude. Nature Human Behaviour, 3(10), 1034. 